\title{
Knowledge attitude and practice (KAP) of diabetes in Mathura, Uttar Pradesh, India - An observational study
}

\author{
Goyal J. ${ }^{1 *}$, Raghav S. $^{2}$, Kumar N. ${ }^{3}$, Singh Bhatia P. ${ }^{4}$, Bajpai P. ${ }^{5}$ \\ DOI: https://doi.org/10.17511/ijmrr.2019.i06.07
}

1* Jyoti Goyal, DNB, Department of Internal Medicine, Nayati Healthcare and Research Centre, Mathura, Uttar Pradesh, India.

2 Seema Raghav, M.Sc., Certified Diabetes Educator, Department of Internal Medicine, Nayati Healthcare and Research Centre, Mathura, Uttar Pradesh, India.

3 Navin Kumar, Ph.D, Biostatistitian, Department of Biostatistics, Nayati Healthcare and Research Centre, Mathura, Uttar Pradesh, India.

${ }^{4}$ Paramjeet Singh Bhatia, MD, Department of Internal Medicine, Nayati Healthcare and Research Centre, Mathura, Uttar Pradesh, India.

5 Purnima Bajpai, B. Pharma., CDE Trainee, Department of Internal Medicine, Nayati Healthcare and Research Centre, Mathura, Uttar Pradesh, India.

Introduction: Objective of this study is to determine the knowledge, attitude and practice regarding type 2 diabetes in diabetics as well as in Non-diabetics and also to determine the knowledge versus practice gap among diabetics. There is almost no study of this kind from Uttar Pradesh region of India. Material and method: A pretested and validated questionnaire were used for assessment of these parameters. This questionnaire was divided in to 3 parts. First part used for assessment of knowledge in all the study subjects and had 8 questions. Second part had five questions based on risk factors and complication of diabetes. Third part was used only for diabetics and again had five questions based on their health care seeking behavior. Results: $50 \%$ of the diabetics are in the age group category of $41-60$ years. $>50 \%$ of non-diabetics are in the age group category 21-40 years. Most of the respondents were aware of symptomatology, noncommunicability, need of self-monitoring of glucose at home and rapidly increasing incidence of diabetes. Almost $70 \%$ of diabetics were aware about foot care and Very nominal number of diabetics $(7.8 \%)$ was consuming sweets daily. A disheartening fact revealed that approximately $87 \%$ of diabetics do not carry sugar candy or any form of sugar before leaving home to correct any hypoglycemic episode. Conclusion: Knowledge of symptomatology of diabetes and requirement of self-monitoring of blood glucose at home was adequate among most of the study subjects and uniformly distributed among diabetics and Nondiabetics. More than $80 \%$ of diabetics were not aware about hypoglycemia symptoms and its treatment.

Keywords: Knowledge attitude and practice, Type II Diabetes, Hypoglycemia

\section{Corresponding Author}

Jyoti Goyal, DNB, Department of Internal Medicine, Nayati Healthcare and Research Centre, Mathura, Uttar Pradesh, India.

Email: jyoti.goyal@nayatihealthcare.com
How to Cite this Article

Goyal J, Raghav S, Kumar N, Bhatia PS, Bajpai P. Knowledge attitude and practice (KAP) of diabetes in Mathura, Uttar Pradesh, India - An observational study. Int J Med Res Rev. 2019;7(6):482-489. Available From

https://ijmrr.medresearch.in/index.php/ijmrr/article/ view/1102
To Browse

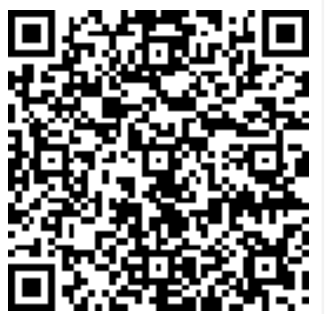

Manuscript Received 2019-10-10

Conflict of Interest No
Review Round 1 2019-10-20

Funding

Nil

Review Round 2
2019-10-30
Ethical Approval
Yes

Review Round 3

Plagiarism X-checker $7 \%$
Accepted 2019-11-05

Note

(c) 2019 by Jyoti Goyal, Seema Raghav, Navin Kumar, Paramjeet Singh Bhatia, Purnima Bajpai and Published by Siddharth Health Research and Social Welfare Society. This is an Open Access article licensed under a Creative Commons Attribution 4.0 International License https://creativecommons.org/licenses/by/4.0/ unported [CC BY 4.0]. 


\section{Introduction}

Diabetes is becoming a major public health problem of developing countries like India because of rapid urbanization and life style changes. At present diabetes is becoming a fastest growing disease in India having prevalence of $8.8 \%$. In India approximately 72 million cases of diabetes were present in 2017 and this figure is expected to double by 2025 . Diabetes is a life-style disease having significant mortality and morbidity associated with its micro-vascular and macrovascular complications; causing huge financial burden on individual as well as on the healthcare system of the country.

Diabetes is a silent killer and may remain undiagnosed for years. Early diagnosis and management of diabetes is essential to prevent and decrease its morbidity and mortality. The main emphasis in management of Diabetes is centered on achieving target sugar levels. Along with pharmacotherapy, diabetic education is an integral part of treatment of diabetes to achieve target glycemic control. Diabetic patients who are empowered with self-care knowledge and education are less prone for diabetic complications and may have better glycemic control. Various studies have proven the role of educational intervention to improve the knowledge and self-care of diabetes and to further minimizing the healthcare problems associated with it [1].

There are very limited studies on assessment of knowledge, attitude and practice from both urban as well as rural part of India and even those which are available; reflect poor awareness among Indian population $[2,3]$. One study which was conducted in Chennai in 2005 yielded that awareness and knowledge regarding the diabetes is grossly inadequate in India and concluded the need of starting diabetes education programs at mass level [4]. Studies from our neighboring countries like Bangladesh and Pakistan also revealed the suboptimal education and knowledge about the diabetes and emphasized on the need of effective diabetes education $[5,6,7]$. UP is classified as one of the 'lagging states of India' for its slow growth, low human development indicators and high concentration of the poor. In view of presence of very limited KAP studies on diabetes from India and especially from western U.P region of India, In the present study, data on this subject to understand the level of knowledge of Diabetes among western
UP population was planned. This data might help in framing policy level intervention making and structured care plan for diabetic patients from this region.

In the study, the assessment of the knowledge and attitude of type II diabetics as well as non-diabetics coming to an Internal Medicine OPD of a tertiary care hospital set-up was done. The present study analyzed health care seeking behavior pattern of all type 2 diabetics included in the study.

\section{Material \& Methods}

Setting: Nayati hospital, which is a Multisuperspeciality hospital situated in Mathura.

Duration of the study: It was carried out over a period of six months from November 2018 to April 2019.

Type of the study: This is an observational study.

Sampling method: Simple random sampling

Sample size calculation: A total of 412 study subjects (206 diabetics and 206 Non-diabetics) were interviewed. It was done by statistician using formula of sample size calculation for observational studies.

\section{Inclusion criteria}

Diabetic/non-diabetic subjects of age between 1865 years with skills of reading and writing; either Hindi or English.

\section{Exclusion criteria}

01. Severe cognitive impairments

02. Critically ill

03. Illiterate

04. Deaf and dumb

\section{Surgical procedure: None}

Ethical consideration: Study was approved by Institutional Ethics committee. There is no conflict of interest and study was conducted after taking informed consents from all the participants and participants' information and data was kept confidential.

Data Collection Procedure: It was conducted in form of a Questionnaire based interview at department of Internal Medicine, Nayati Medicity hospital, Mathura, which is a 350 bedded superSpecialty hospital. 
All study subjects who fulfilled the inclusion criteria were interviewed.

All the study subjects were explained in detail about the purpose of the study and informed consent was taken for their participation and they were assured about the confidentiality and privacy of their responses. Questionnaire was available in Hindi and English language.

Few of the questions in the questionnaire were taken from studies done by Wee et al [8] and Kaniz et al [9] and some were included by us. A pilot study under the guidance of three of the authors (Dr. Jyoti Goyal, Dr. Navin Kumar and Ms. Seema Raghav) was done to pretest the questionnaire which helped in validating this questionnaire before finalizing it. Internal consistency of this questionnaire was found to be 0.74 using cronbach's alpha which had a good level of reliability.

Questionnaire was divided into 3 sections - first section contains demographic profile of study subjects, second section had questions about knowledge, risk factors and complications of diabetes of all study subjects and the last section of the questionnaire included health seeking behavior pattern of diabetic subjects only.

Data Analysis: The collected data was initially entered into Microsoft Excel and then transferred to IBM SPSS 21.0 (Armonk, NY, USA). The number and percentage of gender, age group, marital status, education, occupation, total family member, monthly income, place of residence and family history for diabetic and non-diabetic group were determined. Also, knowledge of respondents toward diabetes, its risk factors, health-seeking behavior and complications were assessed with the help of the questionnaire prepared.

\section{Result}

Socio-demographic characteristics of all study subjects (Table 1) - A total of 412 study subjects were interviewed, after taking the consents, out of which 206 were diabetics and 206 were nondiabetics. Socio-demographic characteristics of the two study groups are as follows: $50 \%$ of the diabetics are in the age group category of $41-60$ years. $>50 \%$ of non-diabetics are in the age group category $21-40$ years. $>30 \%$ of diabetics were $>60$ years of age while approx. $10 \%$ of non-diabetics were coming in this category. $>60 \%$ diabetics and $>85 \%$ non-diabetics were male; while rest of the population were female.
$97.6 \%$ of diabetics and $>60 \%$ of non-diabetics are married.

Table-1: Socio-demographic characteristics of study subjects.

\begin{tabular}{|c|c|c|c|}
\hline Characteristics & Diabetes $(\%)$ & Non-diabetes ( $\%$ ) & Total (\%) \\
\hline \multicolumn{4}{|l|}{ Age (in years) } \\
\hline$\leq 20$ & $3(1.5)$ & $30(14.6)$ & $33(8.0)$ \\
\hline $21-40$ & $34(16.5)$ & $112(54.4)$ & $146(35.5)$ \\
\hline $41-60$ & $103(50.0)$ & $44(21.4)$ & 147 (35.7) \\
\hline$>60$ & $66(32.0)$ & $20(9.7)$ & 86 (20.9) \\
\hline \multicolumn{4}{|l|}{ Gender } \\
\hline Male & $128(62.1)$ & $175(85.0)$ & 303 (73.5) \\
\hline Female & 78 (37.9) & $31(15.0)$ & 109 (26.5) \\
\hline \multicolumn{4}{|l|}{ Marital Status } \\
\hline Unmarried & $5(2.4)$ & $81(39.3)$ & 86 (20.9) \\
\hline Married & $201(97.6)$ & $125(60.7)$ & $326(79.1)$ \\
\hline \multicolumn{4}{|l|}{ Education } \\
\hline Illiterate & $11(5.3)$ & $4(1.9)$ & $15(3.6)$ \\
\hline Primary & $15(7.3)$ & $2(1.0)$ & $17(4.1)$ \\
\hline Middle + Secondary & $55(26.7)$ & $20(9.7)$ & $75(18.2)$ \\
\hline Senior Secondary & $32(15.5)$ & $56(27.2)$ & $88(21.4)$ \\
\hline Graduate & $58(28.2)$ & $97(47.1)$ & $155(37.6)$ \\
\hline Above Graduate & $35(17.0)$ & $27(13.1)$ & $62(15.0)$ \\
\hline \multicolumn{4}{|l|}{ Occupation } \\
\hline Unemployed & $33(16.0)$ & $15(7.3)$ & 48 (11.7) \\
\hline Student & $2(1.0)$ & $67(32.5)$ & $69(16.7)$ \\
\hline Gov. Job & $16(7.8)$ & $7(3.4)$ & $23(5.6)$ \\
\hline Pvt. Job & $30(14.6)$ & $57(27.7)$ & $87(21.1)$ \\
\hline Businessman & $45(21.8)$ & $18(8.7)$ & $63(15.3)$ \\
\hline Farmer & $8(3.9)$ & $22(10.7)$ & $30(7.3)$ \\
\hline House maker & $72(35.0)$ & $20(9.7)$ & $92(22.3)$ \\
\hline \multicolumn{4}{|l|}{ Total family member } \\
\hline$<5$ & $66(32.2)$ & $58(28.2)$ & $124(30.2)$ \\
\hline $5-8$ & $105(51.2)$ & $129(62.6)$ & $234(56.9)$ \\
\hline$>8$ & $34(16.6)$ & $19(9.2)$ & $53(12.9)$ \\
\hline \multicolumn{4}{|c|}{ Monthly income (in rupees) } \\
\hline$\leq 10000$ & $65(31.6)$ & $80(38.8)$ & $145(35.2)$ \\
\hline 10001-20000 & $23(11.2)$ & $48(23.3)$ & $71(17.2)$ \\
\hline 20001-30000 & $42(20.4)$ & $29(14.1)$ & $71(17.2)$ \\
\hline $30001-40000$ & $17(8.3)$ & $21(10.2)$ & $38(9.2)$ \\
\hline$>40000$ & $59(28.6)$ & $28(13.6)$ & $87(21.1)$ \\
\hline \multicolumn{4}{|l|}{ Place of residence } \\
\hline Rural & 43 (20.9) & $95(46.1)$ & $138(33.5)$ \\
\hline Urban & $163(79.1)$ & $111(53.9)$ & $274(66.5)$ \\
\hline \multicolumn{4}{|l|}{ Family history } \\
\hline No & $97(47.1)$ & $160(77.7)$ & $257(62.4)$ \\
\hline Yes & 109 (52.9) & $46(22.3)$ & $155(37.6)$ \\
\hline
\end{tabular}

Knowledge of study subjects towards diabetes (Table 2) - The knowledge about diabetes was checked by asking 8 questions to both the groups. 
The responses of all the questions were grouped into 3 categories: Yes, No \& Don't Know. Approximately $50 \%$ of diabetics and $41 \%$ nondiabetics believed that diabetes is not caused by eating more sweets; while, approximately $4.6 \%$ diabetics and $51.9 \%$ non-diabetics believed that it is caused by eating more sweets. Very few (3.4\% diabetics and $6.8 \%$ non-diabetics) were not aware of any association of diabetes with eating sweets.

$>85 \%$ of diabetics and $70 \%$ of non-diabetics were aware that frequent urination and frequent thirst are the main symptoms of diabetes. $>80 \%$ of subjects in both the categories were aware that diabetes is not a communicable disease and it doesn't spread from person to person. $>40 \%$ of non-diabetics think that diabetes is curable while only $25 \%$ in diabetics category think so. $>74.3 \%$ non-diabetics and $62.1 \%$ of diabetics knew that in diabetes either deficiency of insulin or insulin resistance or both.
It is encouraging to know that more than $80 \%$ of diabetics as well as non-diabetics knew that they need to do self-monitoring of glucose at home with the help of glucometer. $>90 \%$ of diabetics as well as non-diabetics think that incidence of diabetes is increasing with time.

Inquiring about their source of knowledge, $>70 \%$ diabetics received it from relatives or diabetic educator; while $14 \%$ gave credit to television and $8 \%$ to newspaper. Among the non-diabetic category, approx. $40 \%$ received the knowledge through television and newspaper, $>30 \%$ from their relatives and $26.2 \%$ through diabetes educator. Contribution of diabetic educator was remarkably less in Nondiabetics, might be explained with the fact that they get seldom opportunity to meet them. As of now most diabetic educators are working in a hospital setup, further raises the possibility of improving their availability at grass root level to increase the awareness on this lifestyle disorder.

Table-2: Knowledge of respondents toward diabetes.

\begin{tabular}{|c|c|c|c|c|}
\hline \multirow[t]{2}{*}{ Knowledge } & \multirow[t]{2}{*}{ Responses } & \multicolumn{3}{|c|}{ Study group (\%) } \\
\hline & & Diabetes & Non-diabetes & Total \\
\hline \multirow[t]{3}{*}{ Do you believe that diabetes is caused by eating more sweet? } & Yes & $96(46.6)$ & $107(51.9)$ & $203(49.3)$ \\
\hline & No & $103(50.0)$ & 85 (41.3) & $188(45.6)$ \\
\hline & Don't Know & $7(3.4)$ & $14(6.8)$ & $21(5.1)$ \\
\hline \multirow[t]{3}{*}{ Frequent urination and frequent thirst are symptoms of diabetes? } & Yes & $176(85.4)$ & $152(73.8)$ & $328(79.6)$ \\
\hline & No & $17(8.3)$ & $21(10.2)$ & $38(9.2)$ \\
\hline & Don't Know & $13(6.3)$ & $33(16.0)$ & $46(11.2)$ \\
\hline \multirow[t]{3}{*}{ Diabetes is a communicable disease that spread from person to person? } & Yes & $22(10.7)$ & $14(6.8)$ & $36(8.7)$ \\
\hline & No & $164(79.6)$ & $172(83.5)$ & $336(81.6)$ \\
\hline & Don't Know & $20(9.7)$ & $20(9.7)$ & $40(9.7)$ \\
\hline \multirow[t]{3}{*}{ Is Diabetes curable? } & Yes & $52(25.2)$ & $87(42.2)$ & $139(33.7)$ \\
\hline & No & $139(67.5)$ & $89(43.2)$ & $228(55.3)$ \\
\hline & Don't Know & $15(7.3)$ & $30(14.6)$ & $45(10.9)$ \\
\hline \multirow[t]{3}{*}{ Diabetes is a condition in which there is resistance to insulin or lack of insulin in the body? } & Yes & $128(62.1)$ & $153(74.3)$ & $281(68.2)$ \\
\hline & No & $8(3.9)$ & $12(5.8)$ & $20(4.9)$ \\
\hline & Don't Know & $70(34.0)$ & $41(19.9)$ & $111(26.9)$ \\
\hline \multirow[t]{3}{*}{ Is diabetic person required to do self-monitoring of glucose at home? } & Yes & $183(88.8)$ & $172(83.5)$ & $355(86.2)$ \\
\hline & No & $18(8.7)$ & $12(5.8)$ & $30(7.3)$ \\
\hline & Don't Know & $5(2.4)$ & $22(10.7)$ & $27(6.6)$ \\
\hline \multirow[t]{3}{*}{ Do you think diabetes is increasing day by day? } & Yes & $195(94.7)$ & $184(89.3)$ & $379(92.0)$ \\
\hline & No & $5(2.4)$ & $6(2.9)$ & $11(2.7)$ \\
\hline & Don't Know & $6(2.9)$ & $16(7.8)$ & $21(5.3)$ \\
\hline \multirow[t]{4}{*}{ What is the source of your knowledge regarding diabetes? } & Television & $29(14.1)$ & 43 (20.9) & 72 (17.5) \\
\hline & Newspaper & $17(8.3)$ & $38(18.4)$ & $55(13.3)$ \\
\hline & Relatives & $82(39.8)$ & $71(34.5)$ & $153(37.1)$ \\
\hline & Diabetes educator & 78 (37.9) & $54(26.2)$ & $132(32.0)$ \\
\hline
\end{tabular}




\section{Knowledge about risk factors and complication} of diabetes (Table 3) - More than $85 \%$ of diabetics and $>75 \%$ of non-diabetics knew that lack of physical activity; obesity and stress are risk factor for diabetes. Approx. $15 \%$ of diabetics were either un-aware of these risk factors or they think that these factors do not matter. Similarly, $81.6 \%$ of diabetics and $66.5 \%$ of non-diabetics knew that this illness is related to our lifestyle.
Approx. $>30 \%$ of non-diabetics were not aware that diabetes is a lifestyle disease. Regarding the complications $>90 \%$ of the diabetics knew that uncontrolled sugar may damage eyes, heart, kidneys and nerves. Likewise, $>90 \%$ of diabetics as well as non-diabetics were aware of the fact that diabetic person should undergo for an annual checkup of eyes, heart, kidneys and foot examination.

Table-3: Various risk factors and complications of diabetes as stated by the participants.

\begin{tabular}{|c|c|c|c|c|}
\hline \multirow[t]{2}{*}{ Risk factors } & \multirow[t]{2}{*}{ Responses } & \multicolumn{3}{|c|}{ Study group (\%) } \\
\hline & & Diabetes & Non-diabetes & Total \\
\hline \multirow[t]{3}{*}{ Lack of physical activity, obesity and stress are risk factors of diabetes? } & Yes & $\mid 177$ (85.9) & $157(76.2)$ & $334(81.1)$ \\
\hline & No & $19(9.2)$ & $28(13.6)$ & $47(11.4)$ \\
\hline & Don't Know & $10(4.9)$ & $21(10.2)$ & $31(7.5)$ \\
\hline \multirow[t]{3}{*}{ Do you think Diabetes is related with our lifestyle? } & Yes & $|168(81.6)|$ & $137(66.5)$ & $305(74.0)$ \\
\hline & No & $26(12.6)$ & $42(20.4)$ & $68(16.5)$ \\
\hline & Don't Know & $12(5.8)$ & $27(13.1)$ & $39(9.5)$ \\
\hline \multirow[t]{3}{*}{ The eyes can be illuminated due to uncontrolled sugar? } & Yes & $194(94.2)$ & $152(73.8)$ & $346(84.0)$ \\
\hline & No & $2(1.0)$ & $21(10.2)$ & $23(5.6)$ \\
\hline & Don't Know & $10(4.9)$ & $33(16.0)$ & $43(10)$ \\
\hline \multirow[t]{3}{*}{ Uncontrolled sugars can cause damage to Heart, Kidney and Nerves? } & Yes & $190(92.2)$ & $165(80.1)$ & $355(86.2)$ \\
\hline & No & $2(1.0)$ & $7(3.4)$ & $9(2.2)$ \\
\hline & Don't Know & $14(6.8)$ & $34(16.5)$ & $48(11.7)$ \\
\hline \multirow[t]{2}{*}{ Diabetes Person should undergo for an annual check-up of eyes, heart, kidneys, teeth and foot examination? } & Yes & $190(92.2)$ & $187(90.8)$ & 377 (91.6) \\
\hline & No & $5(2.4)$ & $3(1.5)$ & $8(1.9)$ \\
\hline
\end{tabular}

\section{Healthcare seeking behavior of diabetic} patients (Table 4) - Diabetics were asked about their healthcare seeking behavior in form of 7 questions: a question regarding their physical activity was asked in form of the duration of their daily exercises. $>50 \%$ of the diabetics do not exercise at all. $4 \%$ do it for $>45$ minutes daily. Approx. $20 \%$ do it for $30-45$ minutes and $28.2 \%$ do it for $<30$ minutes. A question regarding the awareness of hypoglycemia management was asked and approx.

$87 \%$ diabetics do not keep any candy or sugar with them before leaving home; which is a disheartening figure and emphasized the need of hypoglycemia education to be made mandatory for all diabetics who are on anti-diabetic drugs. Asking about their frequency of consulting a doctor for their sugar control, $>30 \%$ visit every month, $>30 \%$ visit as per doctor's advice; approx. $20.4 \%$ visit every 6 monthly and $12 \%$ visit every year. Asking about their foot care practice approx. $>70 \%$ do not clean their feet with water and do not apply oil or cream before sleeping; only $30 \%$ are doing good foot care.
$65 \%$ of diabetics were regularly checking their blood sugar with glucometer while $35 \%$ were not doing the same. More than $40 \%$ of diabetics were not eating sweets at all and approx. 50\% are eating sweets 2-3 times in a week. Only $7.8 \%$ of diabetics were eating sweets daily.

Table-4: Healthcare-seeking behavior of the diabetic patients.

\begin{tabular}{|l|l|l|}
\hline \multicolumn{1}{|c|}{ Item } & Response & \multicolumn{1}{|c|}{$\begin{array}{c}\text { Diabetic } \\
\text { patients (\%) }\end{array}$} \\
\hline \multirow{4}{*}{ How long do you exercise daily? } & $<30 \mathrm{~min}$ & $47(22.8)$ \\
\cline { 2 - 3 } & $30-45 \mathrm{~min}$ & $41(19.9)$ \\
\cline { 2 - 3 } & $>45 \mathrm{~min}$ & $9(4.4)$ \\
\cline { 2 - 3 } & Never & $109(52.9)$ \\
\hline \multirow{2}{*}{$\begin{array}{l}\text { (carbohydrate) before you leave home? } \\
\text { Do you smoke or any other addiction? }\end{array}$} & Yes & $26(12.6)$ \\
\cline { 2 - 3 } & No & $180(87.4)$ \\
\hline How frequently do you consult a doctor for & Yes & $28(13.6)$ \\
\cline { 2 - 3 } your sugar control? & No & $178(86.4)$ \\
\cline { 2 - 3 } & 1 month & $6(2.9)$ \\
\cline { 2 - 3 } & 6 months & $42(20.4)$ \\
\hline
\end{tabular}




\begin{tabular}{|c|c|c|}
\hline & 1 year & 25 (12.1) \\
\hline & $\begin{array}{l}\text { Doctor's } \\
\text { advice }\end{array}$ & 64 (31.1) \\
\hline \multirow{2}{*}{$\begin{array}{l}\text { Do you clean your feet with water every day before } \\
\text { sleeping, and applies some oil or cream? }\end{array}$} & Yes & 64 (31.1) \\
\hline & No & $142(68.9)$ \\
\hline \multirow{2}{*}{$\begin{array}{l}\text { Do you check your blood sugar by glucometer at } \\
\text { home? }\end{array}$} & Yes & $134(65.0)$ \\
\hline & No & 72 (35.0) \\
\hline \multirow{3}{*}{ How often do you eat sugar / sweets? } & Never & 88 (42.7) \\
\hline & Daily & $16(7.8)$ \\
\hline & $\begin{array}{l}2-3 \text { times } \\
\text { a week }\end{array}$ & $102(49.5)$ \\
\hline
\end{tabular}

\section{Discussion}

Knowledge of participants towards diabetes was assessed with the help of 8 questions asked from each participant. Approximately $50 \%$ of the participant think that diabetes is caused by eating sweets, reflecting poor understanding of pathophysiology of diabetes. This belief was uniformly distributed in diabetics as well as in nondiabetics. Most of the people (more than $80 \%$ ) knew that diabetes is not a communicable disease; more than $30 \%$ of respondents thought that diabetes is curable. Non-diabetics $(42 \%)$ in comparison to diabetics $(25 \%)$, had this misconception.

Approximately $80 \%$ of respondents are aware of symptomatology of diabetes (frequent urination and thirst) that too is almost uniformly distributed among diabetics and non-diabetics. More than $80 \%$ diabetics as well as non-diabetics knew about the need of self-monitoring of blood glucose at home. Approximately $70 \%$ of respondents knew regarding the mechanism of development of diabetes which may be either due to lack of insulin or insulin resistance. More than $90 \%$ of people are aware that diabetes is increasing in incidence very rapidly.

The most common source of knowledge regarding the diabetes is either relatives or diabetic educator. Television, newspaper, and mass media can play a crucial role in increasing the awareness about these life style diseases and as per the present study its contribution was only $20 \%$, further signifies tremendous scope of improvement and to start education campaigns based on improving the awareness about all lifestyle disorders.

The mass and print media have a huge responsibility of providing evidence base scientific information in a very clear and non-confusing manner.
Overall knowledge towards diabetes was found to be average among diabetics as well as non-diabetics. Our finding was similar to the studies done from other developing Asian countries like Bangladesh where knowledge regarding the diabetes was acceptable for everyone [7]. In the present study, knowledge assessed by the questionnaire was not significantly different among diabetics and nondiabetics, in contrast to some other studies where knowledge of diabetics was better in comparison to non-diabetics $[10,11,12]$.

The most common misconception in the present study was related to etiology of diabetes suggesting that eating sweets can cause diabetes, secondly $1 / 3$ rd of the respondents think that it is curable, and this misconception is more common among nondiabetics $(42.2 \%)$ in comparison to diabetics $(25.2 \%)$. However, most of the respondents were aware of symptomatology, non-communicability, need of self-monitoring of glucose at home and rapidly increasing incidence of diabetes.

There are various questions to assess the knowledge about the risk factors and complications of diabetes. The two most common risk factors are lack of physical activity and over-weight or obesity. Surprisingly, more than $80 \%$ of the people were aware about these two common risk factors. Similarly, long term complications of diabetes can affect eyes, heart, kidney, nerves are known by more than $80 \%$ of the respondents. Diabetics were more aware of the long-term complications of the diabetes.

The need of routine health check-up consisting of eyes, heart, kidneys, teeth and foot examination was known by more than $90 \%$ of the respondents and similar in diabetics and non-diabetics population. The knowledge of long-term complications of diabetes help in better compliance for the medications and adoption of healthy lifestyle further reducing the medical and financial burden of it and its complications $[13,14]$.

In this study health care seeking behavior and practices are judged in diabetic subjects only. Asking about the duration of exercise, most of the respondents are doing exercises for $<45$ minutes a day which is less than the prescribed norms suggested by the American Diabetes Association. A very discouraging finding was detected in this study in which more than $80 \%$ of the diabetics were not aware of need of keeping refined sugar or toffee with them whenever they leave their house. 
Hypoglycemia awareness and management is an integral part of diabetic care and it is absolutely essential to impart the knowledge about it to every diabetic who is on pharmacotherapy, be it, oral or Insulin. It is heartening to see that $>80 \%$ of diabetics were not having any form of addiction. Smoking and alcohol among diabetics are very detrimental for its long-term control and management.

Approximately $>60 \%$ of the diabetic patients consult their doctor either as per doctor's advice or every monthly, though nominal amount (12\%) of respondents do not come for follow-up for more than a year. Knowledge regarding the foot care is suboptimal in approx. $70 \%$ of the diabetics. $65 \%$ of the diabetics were checking their blood sugar at home with the help of glucometer while 35\% of them were not aware about the need of it. Very encouragingly $85 \%$ of patients were either not having sweets or having it occasionally 2-3 times in a week; only approx. $8 \%$ people were consuming sweets daily.

\section{Limitation}

As this study was conducted in Internal Medicine OPD of a tertiary care hospital situated in Mathura, it might not truly represent the western UP population. Study is conducted in a hospital-based setting where diabetic educators are available and education with help of leaflets and videos displayed in hospital premises is being provided, may also impact the study conclusion. Therefore, the reliability and applicability of this study conclusion is limited in consideration with general population of Uttar Pradesh.

\section{Conclusion}

More than $50 \%$ of diabetics as well as Nondiabetics were poorly informed about the pathophysiology of Diabetes. Knowledge of symptomatology of diabetes and requirement of self-monitoring of blood glucose at home was adequate among most of the study subjects and uniformly distributed among diabetics and Nondiabetics.

More than $80 \%$ of diabetics were not aware about hypoglycemia detection and management, raises a big concern and puts health care professional into an obligation to impart knowledge on symptoms and correction of hypoglycemia. Also, there should be some processes or protocol in place to ensure its compliance.
Adequate foot care knowledge is present in approx. $70 \%$ of the diabetics in the present study. Most ( $>85 \%$ ) of diabetics are usually keeping away from sweets.

\section{What the study adds to the existing knowledge?}

To improve the information on diabetes and to decrease the gaps between knowledge and practice, it is important to pay attention on training of health care providers and improve the quality of diabetes education through various approaches like word of mouth, diabetic educator, utilizing mass media and by conducting various awareness lectures and seminars at grass root level. As this kind of study have never been conducted from Uttar Pradesh region of India, this might give us some insight about the knowledge, attitude and perception of Diabetes from this area and help us in developing and Planning some educational tools and programs for further increasing the awareness and understanding about Diabetes among the population of this region.

\section{Author's contributions}

Dr. Jyoti Goyal: Overall supervision of the research work, validation of questionnaire. Ms. Seema Raghav: Data compilation, validation of questionnaire. Dr. Navin Kumar: Sample size calculation, statistical analysis of data, validation of questionnaire. Dr. Paramjeet Singh Bhatia: Data Collection, data entry and preparation of master sheet on MS-Excel. Ms. Purnima Bajpai: Manuscript preparation

\section{Acknowledgement}

Authors would like to express our sincere gratitude to Ms. Niira Radia for her continuous support, guidance, motivation and providing all the infrastructural support for this research project and without her help this research would not have been completed.

\section{Reference}

01. Tham KY, Ong JJ, Tan DK, How KY. How much do diabetic patients know about diabetes mellitus and its complications?. Annals-Acad Med Singapore. 2004;33(4)503-509.

[Crossref] 
02. Kaur K, Singh MM, Walia I. Knowledge and selfcare practices of diabetics in a resettlement colony of Chandigarh. Ind J Med Sci. 1998;52(8)341-347.

[Crossref]

03. Muninarayana C, Balachandra G, Hiremath SG, Iyengar K, Anil NS. Prevalence and awareness regarding diabetes mellitus in rural Tamaka, Kolar. Int J Diab Develop Count. 2010;30(1)18. doi: 10.4103/0973-3930.60005 [Crossref]

04. Mohan D, Raj D, Shanthirani CS, Datta M, Unwin NC, Kapur A, Mohan V. Awareness and knowledge of diabetes in Chennai-The Chennai urban rural epidemiology study [CURES-9]. JAPI. $2005 ; 53 ; 283-287$.

[Crossref]

05. Badruddin N, Basit A, Hydrie MZ, Hakeem R. Knowledge, attitude and practices of patients visiting a diabetes care unit. Pak J Nutri. 2002;1(2)99-102.

doi: $10.3923 /$ pjn.2002.99.102 [Crossref]

06. Saleh F, Mumu SJ, Ara F, Ali L, Hossain S, Ahmed KR. Knowledge, attitude and practice of type 2 diabetic patients regarding obesity- study in a tertiary care hospital in Bangladesh. J Pub Health Afr. 2012;3(1)e8.

doi: 10.4081/jphia.2012.e8 [Crossref]

07. Saleh F, Mumu SJ, Ara F, Begum HA, Ali L. Knowledge and self-care practices regarding diabetes among newly diagnosed type 2 diabetics in Bangladesh- a cross-sectional study. BMC Pub Health. 2012;12(1)1112.

doi: 10.1186/1471-2458-12-1112 [Crossref]
08. Wee HL, Ho HK, Li SC. Public awareness of diabetes mellitus in Singapore. Singapore Med J. 2002;43(3)128-134.

[Crossref]

09. Fatema K, Hossain S, Natasha K, Chowdhury HA, Akter J, Khan T, Ali L. Knowledge attitude and practice regarding diabetes mellitus among Nondiabetic and diabetic study participants in Bangladesh. BMC Pub Health. 2017;17(1)364. doi: 10.1186/s12889-017-4285-9 [Crossref]

10. Raj CP, Angadi MM. Hospital-based KAP study on diabetes in Bijapur, Karnataka. Indian J Med Spec. 2010;1(2)80-83.

doi:10.7713/ijms.2010.0022 [Crossref]

11. Al Shafaee MA, Al-Shukaili S, Rizvi SG, Al Farsi Y, Khan MA, Ganguly SS, et al. Knowledge and perceptions of diabetes in a semi-urban Omani population. BMC Pub Health. 2008;8(1)249. doi: $10.1186 / 1471-2458-8-249$ [Crossref]

12. Saeed NH. Diabetes-related knowledge, attitude, practice and beliefs among adult diabetic patients attending diabetic consultation clinic in Sulaimani city. Iraq- University of Sulaimani. 2009.

[Crossref]

13. American Diabetes Association. Supplement 1American Diabetes Association: clinical practice recommendations 2000. Diab Care. $2000 ; 23(1)$ S1-116.

[Crossref]

14. Goyder E, Irwig L. Screening for diabetes- what are we really doing?. BMJ. $1998 ; 317(7173) 1644-1646$.

doi: $\quad 10.1136 / \mathrm{bmj} .317 .7173 .1644 \quad$ [Crossref] 